\title{
THE COLUMNAR-TO-EQUIAXED TRANSITION IN NICKEL-BASED SUPERALLOYS
}

\author{
J. W. Fernihough, S. L. Cockcroft, A. Mitchell and A. J. Schmalz \\ The Department of Metals and Materials Engineering \\ The University of British Columbia \\ Vancouver, Canada \\ V6T $1 Z 4$
}

\begin{abstract}
$\underline{\text { Abstract }}$
The thermal conditions leading to the columnar-to-equiaxed transition have been measured in nickel based superalloys AM1 and MAR-M200+Hf. The experimental methodology involved melting and directionally solidifying bars in alumina cylinders induction heated with a Mo susceptor and cooled with a chill located at the bottom. The temperature data obtained from embedded thermocouples clearly revealed a thermal recalesence in the equiaxed zone which was not found to be present in the columnar zone. Thus, the onset of a thermal recalesence was found to coincide well with the CET. The thermocouple data has been processed to yield estimates of the solidification rate $(R)$ and temperature gradient $(G)$ at the solidification front. Two approaches have been used: one based on a straightforward regression analysis of the data; the other, based on tracking the dendrite tip temperature. The latter has been done using the KGT model with the pseudo binary approximation to determine the dendrite tip undercooling $\Delta \mathrm{T}_{\mathrm{C}}$ as a function of growth rate. A comparison of the results obtained for the two techniques is presented. Finally, a modified Hunt CET model has been developed and employed to estimate the nucleation undercooling consistent with the occurrence of the CET at the G and $R$. conditions determined from the isotherm tracking analysis of the thermocouple data.
\end{abstract}

\section{Introduction}

The nucleation of spurious grains during the directional solidification of single crystal castings is held to be related to the columnar-to-equiaxed transition (CET) in so-far-as both phenomena are related to the kinetics of heterogeneous nucleation and dendrite growth. In conventional casting processes, this transition occurs in association with decreasing temperature gradients and increasing growth rates and can occur in a variety of locations depending on the casting process, but generally arises in the last regions of a casting to solidify in association with the dissipation of superheat. The exact conditions under which the transition takes place and the parameters that influence it have not been extensively studied in high temperature systems, although much work has been carried out on low temperature analogue systems.

The objective of this study was to measure accurately the thermal Superalloys 1996

Edited by R. D. Kissinger, D. J. Deye, D. L. Anton

A. D. Cetel, M. V. Nathal, T. M. Pollock, and D. A. Woodford

The Minerals, Metals \& Materials Society, 1996 conditions present at the time of the transition in alloys typical of those employed in the casting of DS and SX aeroengine blades. The thermal conditions identified in the present study provide only one set of limiting conditions for the avoidance of spurious grains during SX casting. This study is part of a larger progranme aimed at developing the data necessary for input to microstructural models capable of predicting the evolution of microstructure, and ultimately the avoidance of spurious grains, in directional solidification processes given a knowledge of the macro and micro heat flow conditions.

\section{Experimental}

The alloys examined in the present study were nickel-based superalloys AM1 and MAR-M200+Hf. The compositions of the two alloys studied are presented in Table $I$.

Table I

Alloy Composition

\begin{tabular}{ccc} 
& AM1 & MAR200+Hf \\
\hline $\mathrm{Ni}$ & bal & bal \\
$\mathrm{Cr}$ & $7.52 \mathrm{wt} \%$ & $8.40 \mathrm{wt} \%$ \\
$\mathrm{Co}$ & $6.64 \mathrm{wt} \%$ & $9.52 \mathrm{wt} \%$ \\
$\mathrm{Mo}$ & $2.06 \mathrm{wt} \%$ & $0.03 \mathrm{wt} \%$ \\
$\mathrm{Al}$ & $5.34 \mathrm{wt} \%$ & $4.98 \mathrm{wt} \%$ \\
$\mathrm{Ti}$ & $1.25 \mathrm{wt} \%$ & $1.92 \mathrm{wt} \%$ \\
$\mathrm{~W}$ & $5.59 \mathrm{wt} \%$ & $11.9 \mathrm{wt} \%$ \\
$\mathrm{Ta}$ & $7.80 \mathrm{wt} \%$ & $0.10 \mathrm{wt} \%$ \\
$\mathrm{Nb}$ & $0.01 \mathrm{wt} \%$ & $0.86 \mathrm{wt} \%$ \\
$\mathrm{Hf}$ & $0.004 \mathrm{wt} \%$ & $1.18 \mathrm{wt} \%$ \\
$\mathrm{C}$ & $80 \mathrm{ppm}$ & $0.14 \mathrm{wt} \%$ \\
$\mathrm{~B}$ & $3 \mathrm{ppm}$ & $150 \mathrm{ppm}$ \\
$\mathrm{Zr}$ & $10 \mathrm{ppm}$ & $400 \mathrm{ppm}$ \\
\hline
\end{tabular}

The experiments, conducted at UBC, involved melting and directionally solidifying bars in alumina cylinders induction heated with a Mo susceptor and cooled with a chill located at the bottom. In the experiments, great care was taken to measure accurately the evolution of temperature in the region of the sample encompassing the CET. This was done by conducting a series of solidification experiments in which a thermocouple probe was frozen at different depths in the sample adjacent to the CET, both in the columnar region and in the equiaxed region. The probe was comprised of two Type-D W-3\%Re /W-25\%Re thermocouples vertically off-set from 


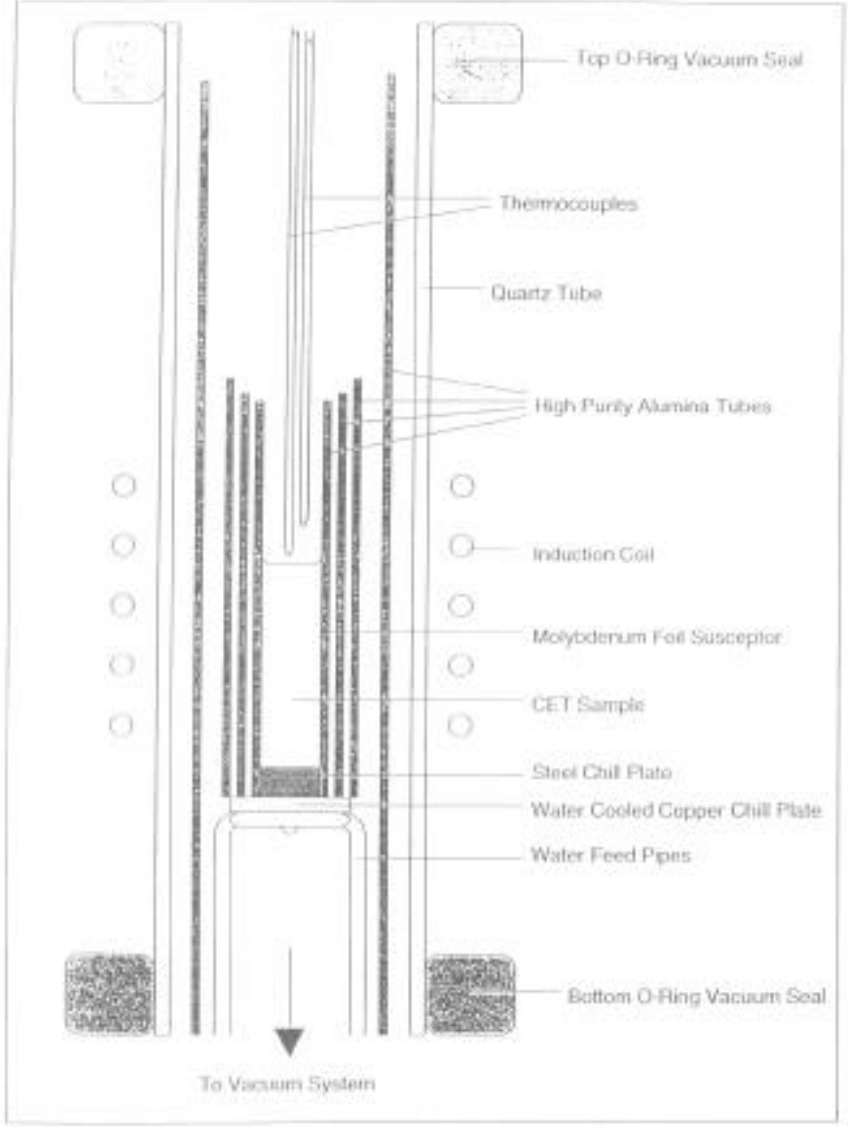

Figure 1: Schematic diagram of vacuum induction furnace.

one another by $12 \mathrm{~mm}$. A typical experimental set-up showing the probe and the sample to be solidified is shown in Figure 1. Effort was made to maintain consistent initial and cooling conditions runto-run. At the completion of a series of runs, the sample was sectioned and etched for metallographic examination. The CET was generally found to occur approximately $2 / 3$ of the way up the har. Alloy composition was measured before and after completion of the runs to asecrtain the extent to which alloy loss had occurred.

Prior to conducting the CET experiments the thermocouples were calibrated using $99.9 \%$ pure nickel in order to assess the run-to-run and absolute accuracy of the measurements. The run-to-run standard deviation was found to be approximately $2^{\circ} \mathrm{C}$ and the absolute accuracy, $16^{\circ} \mathrm{C}$, which falls within the $1 \%$ error inherent in the thermocouple as specified by the manufacturer.

\section{Results and Discussion}

\section{Microstructure}

A polished and etched cross section of a typical CET sample is shown in Figure 2. As can be seen, the transition from columnar to equiaxed is abrupt, but occurs within a range of axial locations across the sample covering approximately $2 \mathrm{~mm}$. No zone of mixed equiaxed and columnar structure was observed in any of the experiments. This result is in agreement with the findings of Wienberg et, $a l[1,2]$ and Hunt and Flood[3] in their examination of the CET in low temperature alloys, but differs from the findings of Pollock et. al. $[4]$ in their examination of grain defect formation

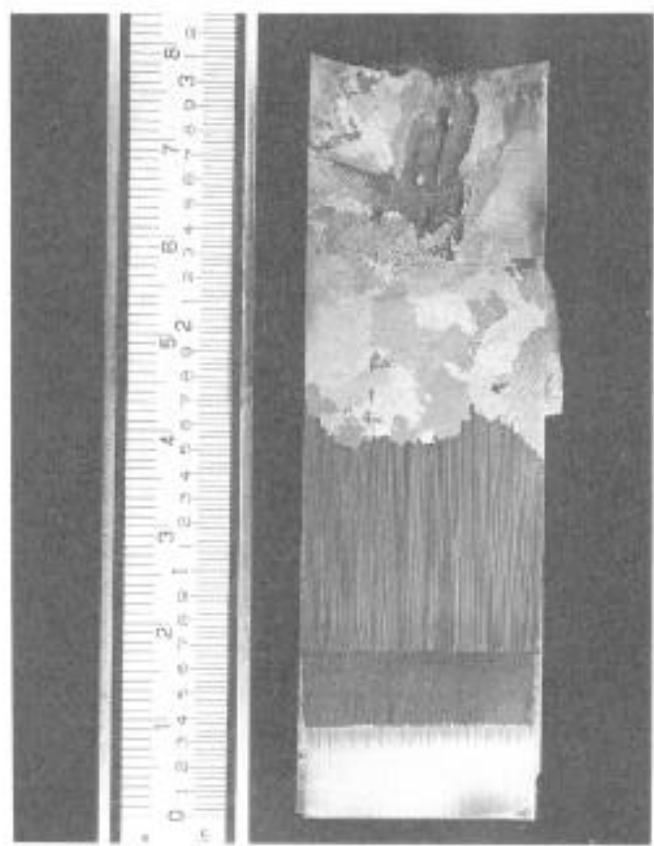

Figure 2: Sectioned and etched sample showing typical CEI observed in AM1.

in directionally cast nickel base single erystals. Further, examination of the dendrite morphologies reveals that the growth is dominated by primary arms right up to the CET, whereas Pollock and co-workers reported a transition preceding the CET from primary to secondary and tertiary growth]4]. Thus, based on this comparison it would appear that the growth conditions, and perhaps the nucleation conditions, prevalent in this study differ substantinlly from the those in the study by Pollock et. al.[4]. The differences in thermal conditions between the two studies are examined in more detail later.

\section{Thermal}

Typical data showing the yariation in temperature with time obtained in a sample of MAR-M200+Hf cooled with the probe placed at various locations is shown plotted in Figure 3. As can be seen, there is a distinct change in the evolution of temperature that occurs between 41 and $46 \mathrm{~mm}$ from the chill, from continuous cooling, indicative of columnar growth, to interrupted cooling (thermal recalesence), typical of equiaxed growth. Fundamentally, the latter behaviour may be attributed to the failure of the local thermal gradient to remove the latent heat ussociated with equiaxed growth at a rate sufficient to maintain continuous cooling. Whether this phenomenon plays a role in the CET or is a consequence of it remains to be established.

An expanded view showing temperature histories obtained with one of the probe thermocouples located in the columnar zone and the other located in the equiaxed zone is shown in Figure 4 . In this figure, there is clearly a thermal recalesence observed in the equiaxed zone which is not present in the colmmnar zone. A review of all of the thermal data from the various experiments revealed that the onset of a thermal recalesence was found to coincide well with the transition from columnar to equiaxed growth. 


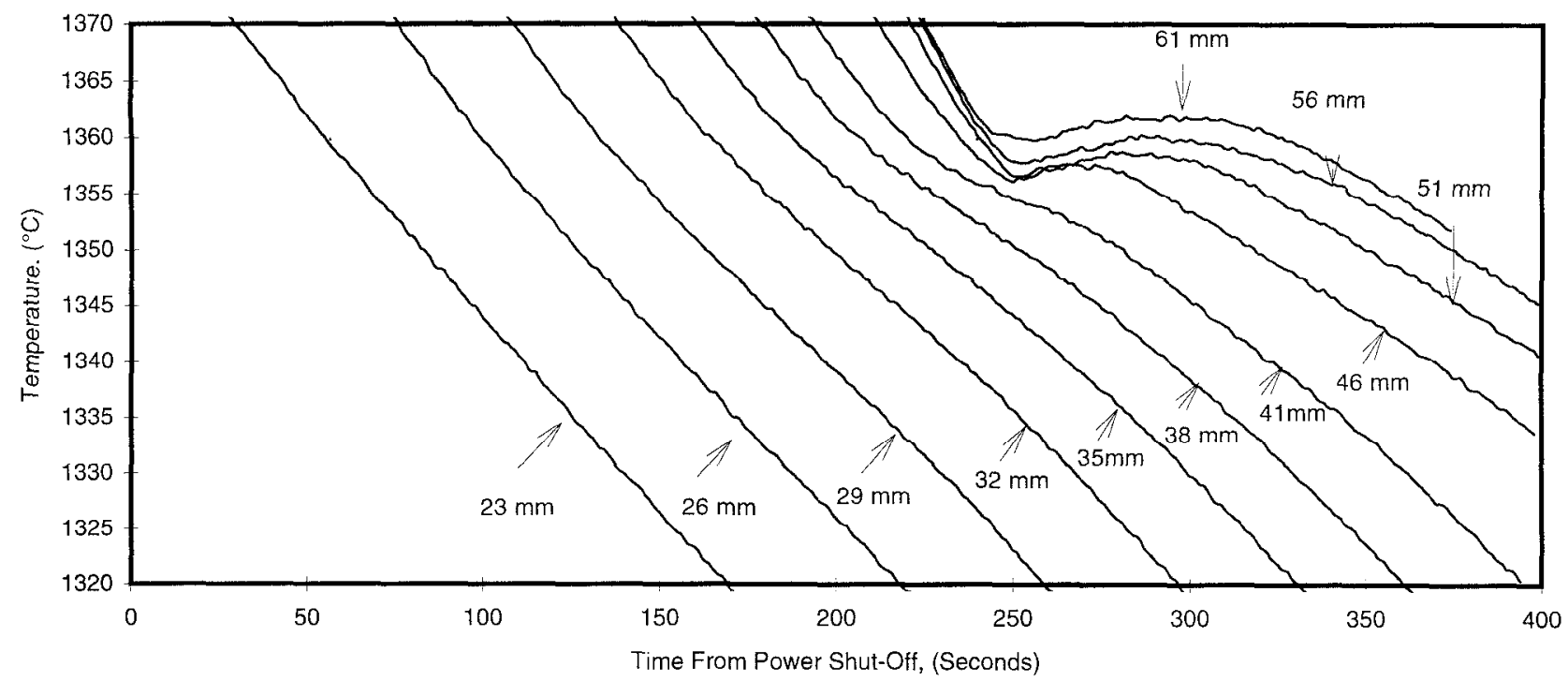

Figure 3: Variation in temperature with time recorded with the thermocouple probe located at various positions.

Since there was a $12 \mathrm{~mm}$ vertical spacing between the probe thermocouples it was not possible to use the data from a single solidification sequence to pinpoint exactly the thermal conditions leading to the CET. Hence, the need to examine multiple solidification sequences with the probe located at various positions. While this approach yielded an improved picture of the variation in temperature in the vicinity of the CET it had a number of drawbacks. Principally, it was found that there were differences in the initial conditions from run-to-run. A sense of the magnitude of the run-to-run variation can be seen in Figure 5, which is a plot of the thermal profiles at 25 s intervals derived on the basis of multiple solidification sequences. As can be seen in the example shown, there is roughly a $20^{\circ} \mathrm{C}$ variation in the initial temperature at between 35 and $45 \mathrm{~mm}$ from the chill. The CET lics within this range. However, it should also be noted that there is some reduction in this variation with increasing time particularly as the liquidus temperature is approached, suggesting that latent heat effects dominate over the variability observed in the superheat.

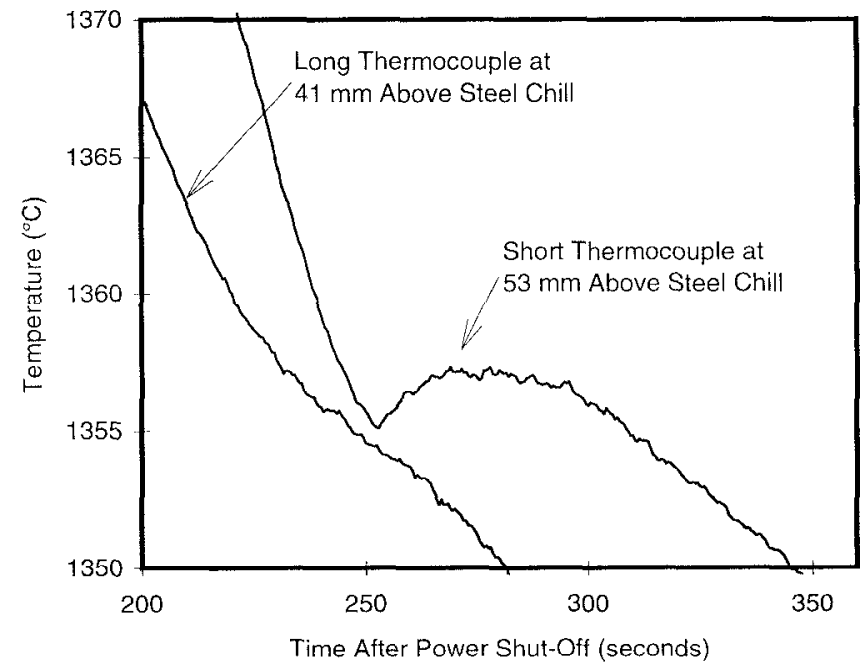

Figure 4: Variation in temperature with time recorded with the thermocouple probe located such that the thermocouples straddled the CET.

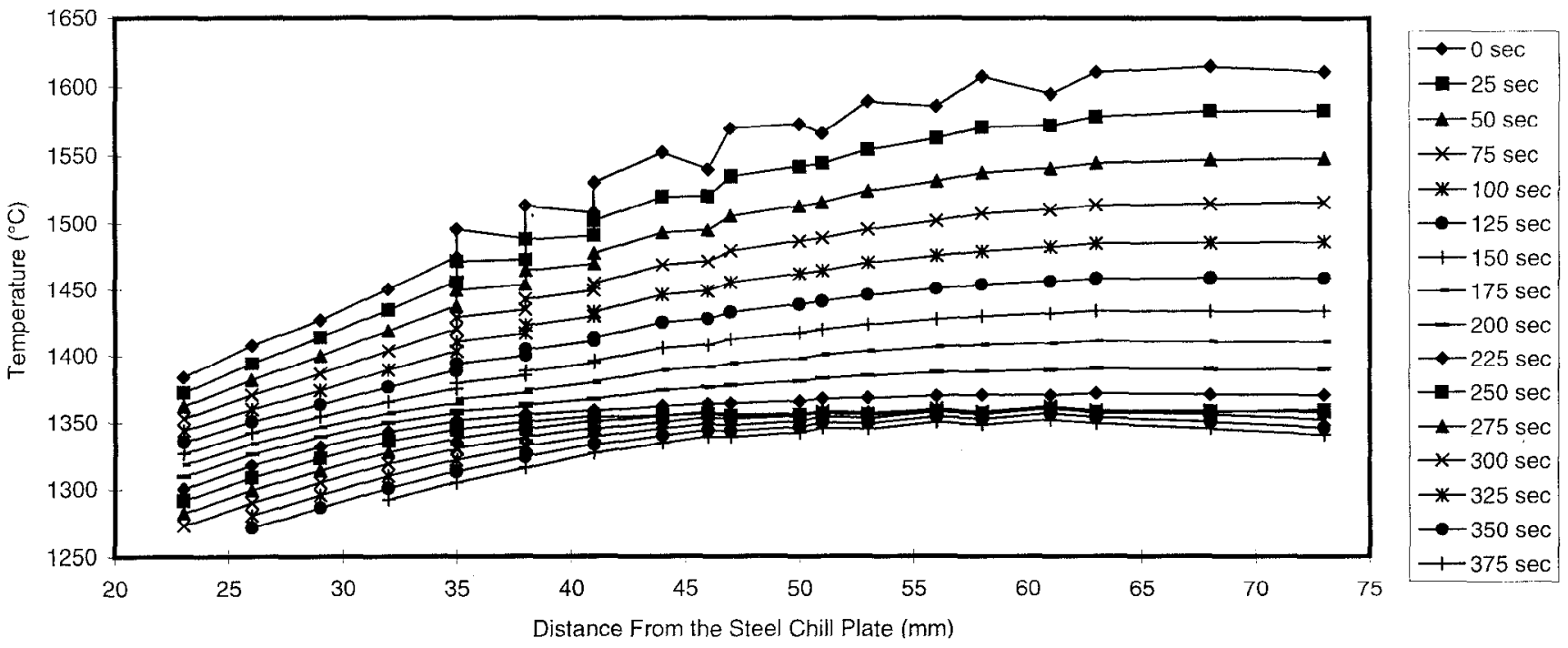

Figure 5: Thermal profiles at 25 second intervals as derived from multiple solidification sequences. 


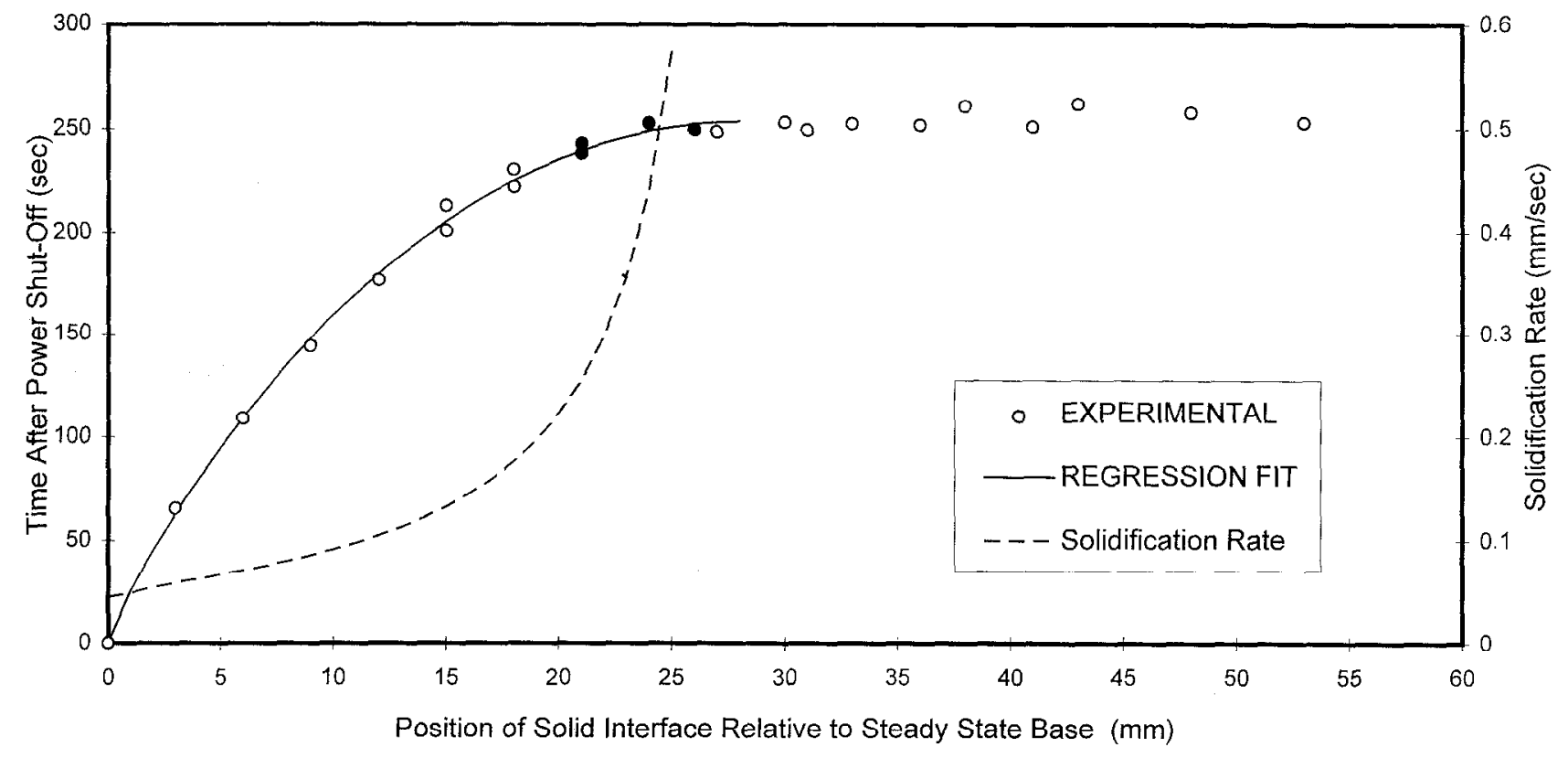

Figure 6: Progress of solid interface position with time and solidification rate.

\section{Analysis}

Given the circumstances described above - i.e. variability in axial position of CET across sample and in initial temperature distribution from run-to-run - extraction of the solidification rate, $\mathrm{R}$, and thermal gradient, $\mathrm{G}$, just prior to the CET presents a significant challenge. Consequently, two procedures were employed to analyze the thermal data. Both methods are essentially isotherm tracking techniques that use as input the thermocouple data. In the first, the isotherm, or temperature, tracked is taken to be the liquidus temperature less the undercooling observed at the onset of equiaxed solidification (as recorded by a thermocouple in the equiaxed regime adjacent to the $\mathrm{CET}$ ). The columnar front position as a function of time was subsequently regression fit with a polynomial, the derivative of which, could then be used to estimate the growth rate, $\mathrm{R}$. The other important solidification parameter, the thermal gradient, $G$, was estimated by regression fitting the thermal data at the time of the CET (as determined from the first appearance of a thermal recalesence).

In the second method, a more accurate estimate of the columnar tip velocity is determined by allowing the isotherm tracked to vary with velocity as dictated by solutal undercooling. The KGT model[5] modified for multicomponent alloys[6] was adopted for this task. The procedure used to accomplish this was to iteratively obtain improved estimates of the dendrite tip temperature, $T_{t i p, i+1}$, by calculating a solutal undercooling, $\Delta T_{C, i}$, based on the isotherm velocity of the original estimate of the dendrite tip temperature, $T_{t i p, i}$. The details of the approach are presented elsewhere [7]. This approach has the advantage that there is a unique isotherm traveling at a rate which corresponds to its undercooling below the equilibrium liquidus temperature. Thus, there is an additional constraint and the error is reduced[7].
Typical results obtained using the first method (referred to as regression analysis) are shown plotted in Figure 6. The discrete points represent the time at which the columnar front passes the location of the probe thermocouples and the solid line represents the regression fit to the discrete values. The solid data points represent the locus of CET positions as estimated based on thermal behaviour (transition from continuous cooling to thermal recalesence).

The method does not lend itself particularly well to an estimate of the solidification rate, $\mathrm{R}$, just prior to the CET as the growth rate is changing rapidly within the limits of the estimated CET position. Utilization of the physical position of the CET instead does not significantly improve the accuracy owing to the variability in the axial position of the CET across the sample and from run-to-run. The same problem arises in attempting to estimate the thermal gradient, $\mathrm{G}$.

The resulting R's and G's obtained for the CET using the two techniques for alloys AM1 and MAR-M200+Hf are presented in Table II. As can be seen from the data presented in Table II the two techniques yield similar results with estimated errors of approximately $50 \%$ for the regression method and around $30 \%$ for the method based on the solutal undercooling.

Arguably the results of this study are not readily transferable to the casting of single crystal turbine blades owing to the fact that breakdown of directional growth has been investigated under conditions of relatively high growth velocity and low thermal gradient. Nonetheless, some or all of the phenomena responsible for the morphological transition under the conditions examined in this study will be at play in the formation of spurious grains in single crystal turbine blades including dendrite growth kinetics and heterogeneous nucleation conditions. 
Table II

Growth Rate and Thermal Gradients from Regression and Isotherm Tracking Analysis

\begin{tabular}{ccccc}
\hline Sample & \multicolumn{2}{c}{ Regression } & \multicolumn{2}{c}{ Dendrite Tip Undercooling } \\
\hline & $\begin{array}{c}\mathrm{R} \\
(\mathrm{mm} / \mathrm{s})\end{array}$ & $\begin{array}{c}\mathrm{G} \\
\left({ }^{\circ} \mathrm{C} / \mathrm{cm}\right)\end{array}$ & $\begin{array}{c}\mathrm{R} \\
(\mathrm{mm} / \mathrm{s})\end{array}$ & $\begin{array}{c}\mathrm{G} \\
\left({ }^{\circ} \mathrm{C} / \mathrm{cm}\right)\end{array}$ \\
AM1-1 & $0.33-0.44$ & $2.6-4.0$ & $.39 \pm .05$ & $4.6 \pm 2.2$ \\
AM1-2 & $0.19-0.33$ & $6.4-10.8$ & $.31 \pm .03$ & $6.9 \pm 1.7$ \\
AM1-3 & $0.22-0.40$ & $3.8-9.1$ & $.23 \pm .05$ & $4.5 \pm 1.3$ \\
AM1-4 & $0.45-0.15$ & $0.0-2.7$ & $.39 \pm .06$ & $5.0 \pm 2.1$ \\
AM1-5 & $0.22-0.46$ & $4.1-9.0$ & $.33 \pm .05$ & $5.6 \pm 1.2$ \\
MAR-1 & $0.33-0.60$ & $4.7-7.2$ & $.37 \pm .04$ & $4.3 \pm 1.1$ \\
MAR-2 & $0.33-0.50$ & $4.7-7.2$ & $.39 \pm .04$ & $7.5 \pm 2.3$ \\
MAR-3 & $0.32-0.49$ & $4.5-7.9$ & $.39 \pm .06$ & $6.0 \pm 1.5$ \\
MAR-4 & $0.34-0.50$ & $0.07-2.8$ & $.35 \pm .05$ & $4.1 \pm 2.2$ \\
MAR-5 & $0.28-0.45$ & $3.3-8.1$ & $.36 \pm .04$ & $6.7 \pm 2.6$ \\
\hline Note: MAR is an abbreviation for MAR-M200+Hf
\end{tabular}

To investigate nucleation phenomena in these two alloys, a modified IIunt[8] CET model has been developed and employed[7,9] to estimate the nucleation undercooling necessary to give rise to a CET under the growth conditions determined from the isotherm tracking analysis of the thermocouple data. As the Hunt [8] model is based on an assessment of the extended volume fraction of equiaxed grains ahead of the columnar dendritic front an estimate of the gradient in the liquid has been used instead of the previously estimated gradient at the tip. These results of the analysis are shown in Table III for nucleation populations of 4 and 24 per $\mathrm{cm}^{3}$. These values represent the range in number of equiaxed grains per $\mathrm{cm}^{3}$ observed in the samples.

Table III

Heterogeneous Nucleation Undercooling

\begin{tabular}{cccc}
\hline Sample & $\begin{array}{c}\text { Average } \mathrm{R} \\
(\mathrm{mm} / \mathrm{s})\end{array}$ & $\begin{array}{c}\mathrm{G}_{\text {Liguid }} \\
\left({ }^{\circ} \mathrm{C} / \mathrm{cm}\right)\end{array}$ & $\begin{array}{c}\Delta \mathrm{T}_{\mathrm{N}} \\
\left({ }^{\circ} \mathrm{C}\right)\end{array}$ \\
\hline AM1, $\mathrm{N}_{0}=4$ & $0.32 \pm 0.05$ & $1.60 \pm 0.59$ & $3.5 \pm 0.6$ \\
AM1, $\mathrm{N}_{0}=24$ & $0.32 \pm 0.05$ & $1.60 \pm 0.59$ & $3.7 \pm 0.4$ \\
MAR-M200+Hf, & $0.38 \pm 0.04$ & $1.47 \pm 0.39$ & $3.5 \pm 0.4$ \\
$\begin{array}{c}\mathrm{N}_{0}=4 \\
\text { MAR-M200+Hf, } \\
\mathrm{N}_{0}=24\end{array}$ & $0.38 \pm 0.04$ & $1.47 \pm 0.39$ & $3.8 \pm 0.3$ \\
\hline
\end{tabular}

As is evident from the data in Table III the undercooling predicted for the two alloys is similar with the difference falling within the uncertainty. The heterogeneous nucleation undercoolings of 3.5$3.8^{\circ} \mathrm{C}$ predicted using this technique are only slightly higher than the thermal recalesence measured in the experiments $\left(1.0-3.2^{\circ} \mathrm{C}\right)$. Furthermore, they are consistent with those found in the platform of directionally solidified turbine blades[10] which would explain the tendency to form spurious grains in the platform section of blades.

\section{$\underline{\text { Summary and Conclusions }}$}

The thermal conditions leading to the CET in single crystal alloys AM1 and MAR-M200+Hf have been examined in detail using data obtained from directionally solidified samples. A number of techniques have been utilized in an attempt to estimate the growth conditions ( $R$ and $G$ ) leading to the CET from the thermocouple data. In comparison to other investigations [4] [10], the solidification conditions examined in this study in association with the CET are substantially different and have focused on higher solidification rates and lower gradients. In respect of the work of Pollock et. al.[4], this may well explain the difference in growth morphology and transition morphology found in the two studies. Consequently, the two studies may well be examining two different mechanisms which can give rise to a breakdown in directional growth - one operating at high growth velocities and low gradients the other a low velocities and high gradients.

Analysis of the results with a Hunt-based CET model predict heterogeneous nucleation undercoolings of the order of those found in the platform section of directionally solidified blades. Thus, it is possible that a Hunt-based CET model can be used to help predict the onset of spurious grain formation in the platform section of SX turbine blades providing data of the type measured in this investigation is available for the alloy systems under investigation.

Finally, measurements of the type made in this study are extremely difficult to make even in low temperature systems. While the results are arguably approximate from the standpoint of their uncertainty, and, their inability to be directly applied to single crystal castings, they are an important contribution as they lay the foundation for the determination of critical data needed for the development of process analysis tools for the design of casting systcms. 


\section{References}

[1] Mahapatra, R.B., Weinberg, F. "Columnar to Equiaxed Transition in Tin-Lead Alloys." Metallurgical Transactions B, Vol. 18B, June 1987, pp.425-432.

[2] Ziv, I., Weinberg, F. "The Columnar to Equiaxed Transition in Al 3pet Cu", Metallurgical Transactions B, Vol. 20B, Oct. 1989, pp.731-734.

[3] Hunt, J.D. and Flood, S.C. "Columnar to Equiaxed Iransition", Metals Handbook, 9th Edition, Vol 15. ASM International 1988, pp.130-136.

[4] Pollock, T.M., Murphy, W.H., Goldman, E.H., Uram, D.L. and Tu, J.S., "Grain Defect Formation During Directional Solidification of Nickel Base Single Crystals", Proceedings of a Conference: Superalloys 1992. pp. 125-134, Pub. The Minerals, Metals and Materials Society, 1992.

[5] Kurz, W., Giovanola, B. and Trivedi, T.R.: Acta Metall., vol. 34 (1986), No. 5 , pp. 823-30.

[6] Rappaz, M., David, S.A., Vitek, J.M. and Boatner, L.A: Metall. Trans A, vol. 21A(1990), pp.1767-82.

[7] Fernihough, J.W., Ph.D. Thesis, "The Columnar to Equiaxed Transition in Nickel Based Superalloys AM1 and MARM200+Hf", The University of British Columbia, 1995.

[8] Hunt, J.D., "Steady State Columnar and Fquiaxed Growth of Dendrites and Eutectic", Materials Science and Engineering, vol. 65 (1984) 75-83.

[9] Cockcroft, S.L., Rappaz M., Mitchell A., Fernihough, J.W. and Schmalz, A., "An Examination of Some of the Manufacturing Problems of Large Turbine Blades for use in Land Based Gas Turbines", Materials for Advanced Power Engineering 1994, ed. D. Coutsouradis, publ. Kluwer Press, Belgium.

[10] Goldschmidt, D., Paul, U., Sahm, P.R., "Porosity Clusters and Recrystallization in Single Crystal Components', Proceedings of a Conference: Superalloys 1992. pp. 125-134, Pub. The Minerals, Metals and Materials Society, 1992. 